Engineering Note 3823.130-EN-522

:

\title{
A LAYER MDT OCTANT SUPPORT ANALYSIS
}

BY: Tony Levand March 23,2000

CHECKED: Rlt Ro 


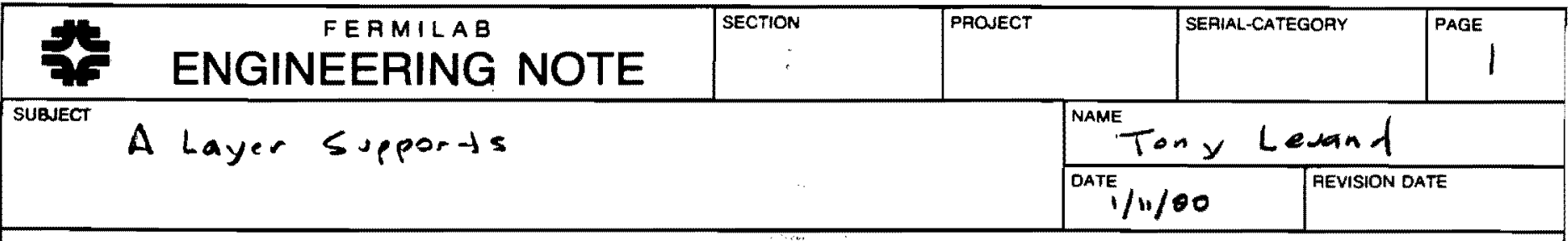

DRY 3823.130. HC. 373555 SUPPORT IS BOLTFO

T० 373937 of 373973

SUPPORT WELDMENT

LOAPS:

TATERHA : ASTMA-3CHE FLAT

$$
\begin{aligned}
& \frac{\text { OCTHNC WEIGHT }}{2}=400 \mathrm{lbs} \\
& \left.3.5\right|_{100} ^{1} \\
& F T y=36 \mathrm{ks} \\
& F_{\text {Albu }}=\frac{36}{3}=12 \mathrm{ksl} \text { Tensile Albutt } \\
& F_{s}=\frac{F_{\text {allow }}}{2}=6 \mathrm{ks} \text { Shers Allawhble }
\end{aligned}
$$

WELP AVALTSIS:

$r=400 \times 5.16=2064:$ ibs

1/4 weld, AsSUME OJTSIDE WELOS ONEY, DAREUT MATERIML

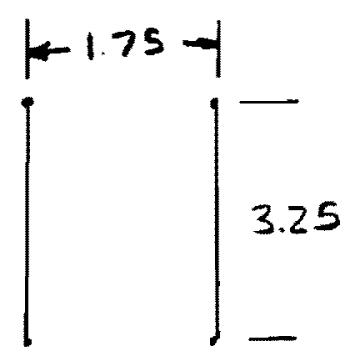

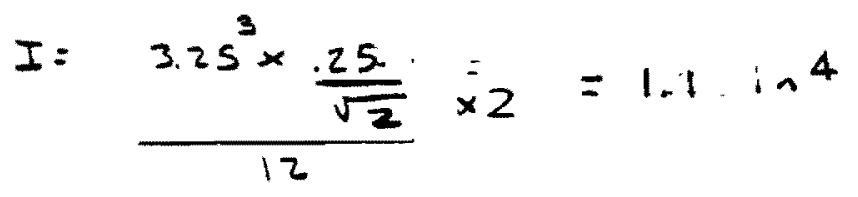$$
f_{b}=\frac{11 c}{I}=\frac{2069 \times \frac{3.25}{2}}{1.1}=3.4 \mathrm{ks} / 12 \mathrm{ksI}
$$$$
\text { Shar }=\frac{400}{3.25 \times 2 \times} \times \frac{25}{\sqrt{2}}=349 \mathrm{PSI}
$$

\section{BOLT TEMSION:}

$P_{-14}=\frac{H}{D}=\frac{2069}{2.5 \times 2}=413 \mathrm{lbs}$

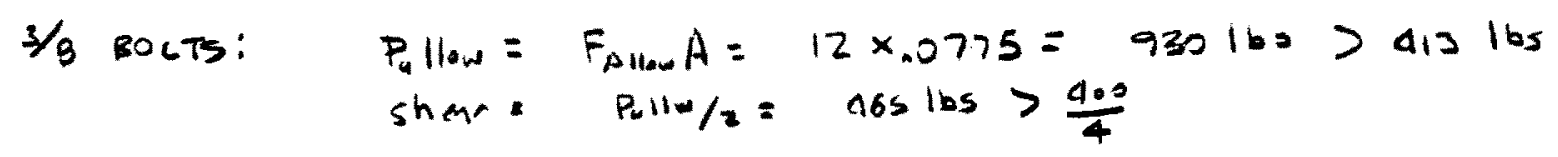




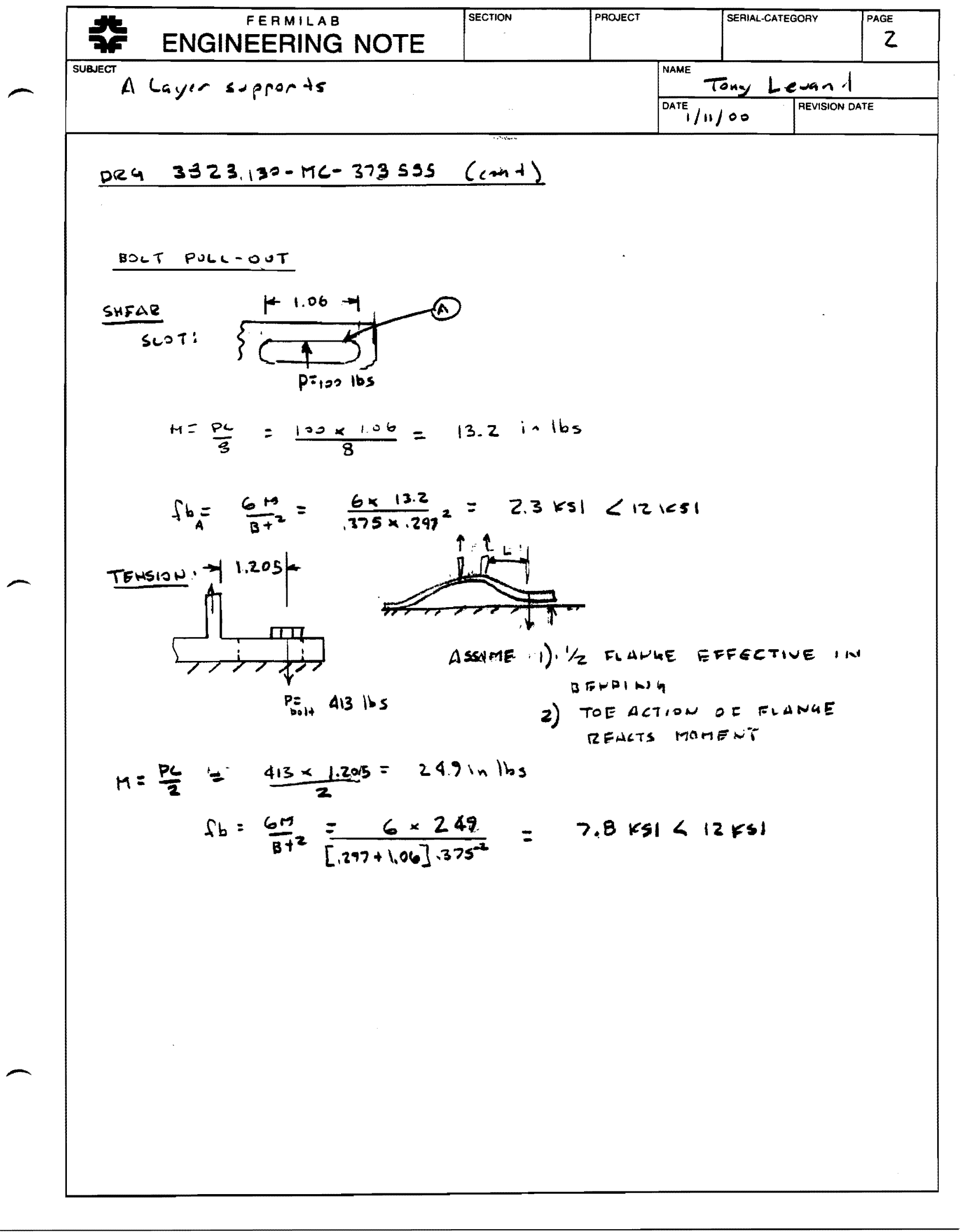




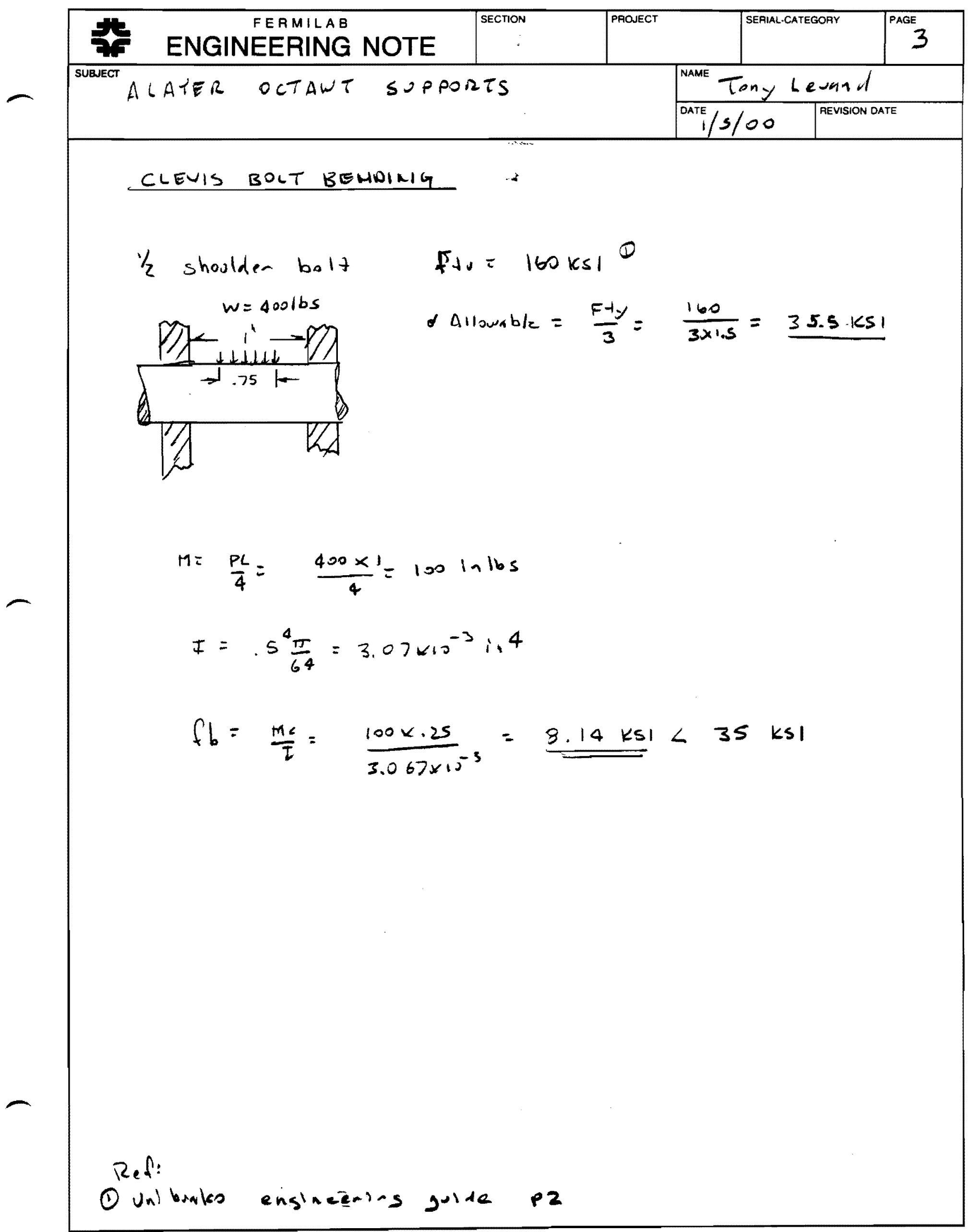




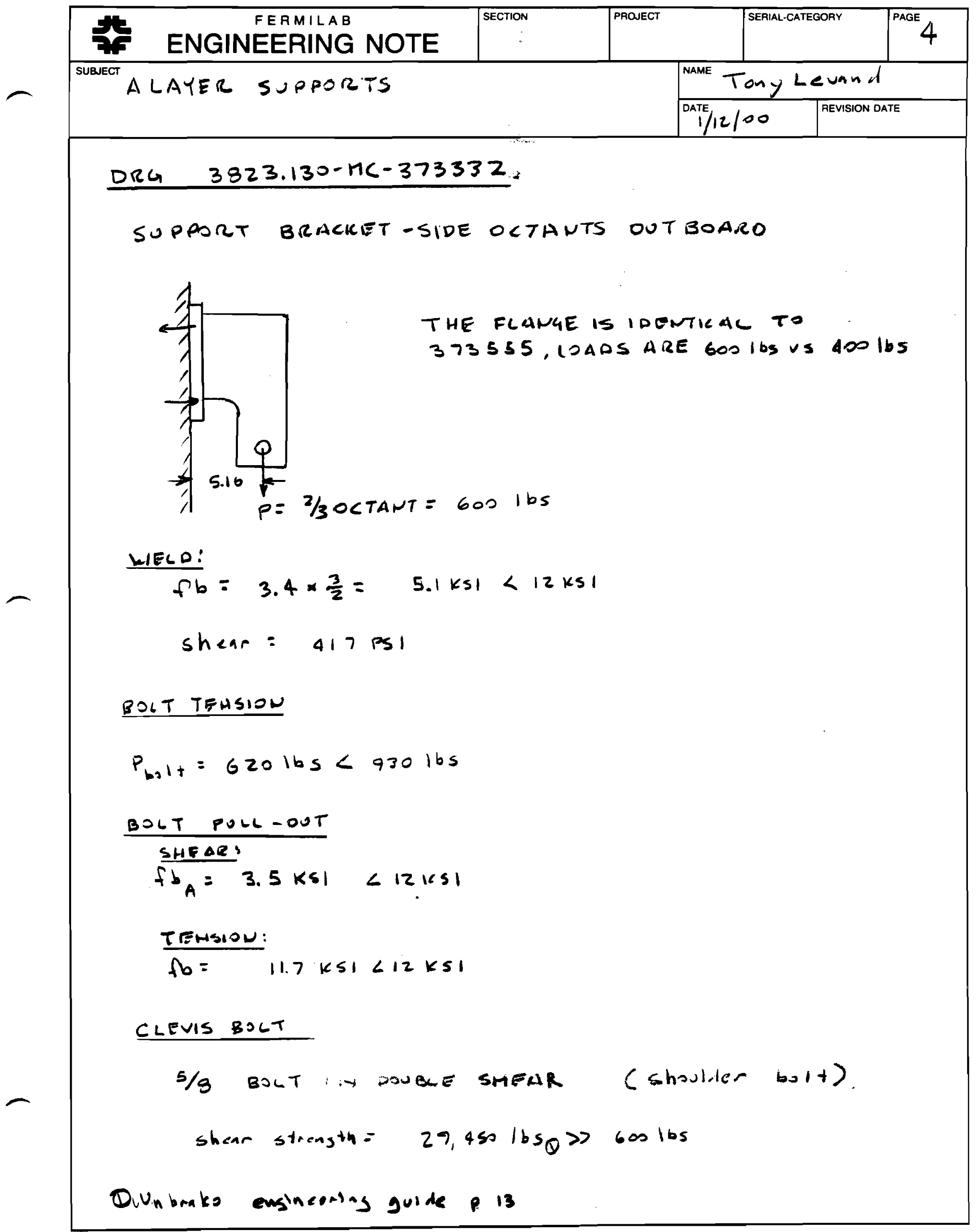




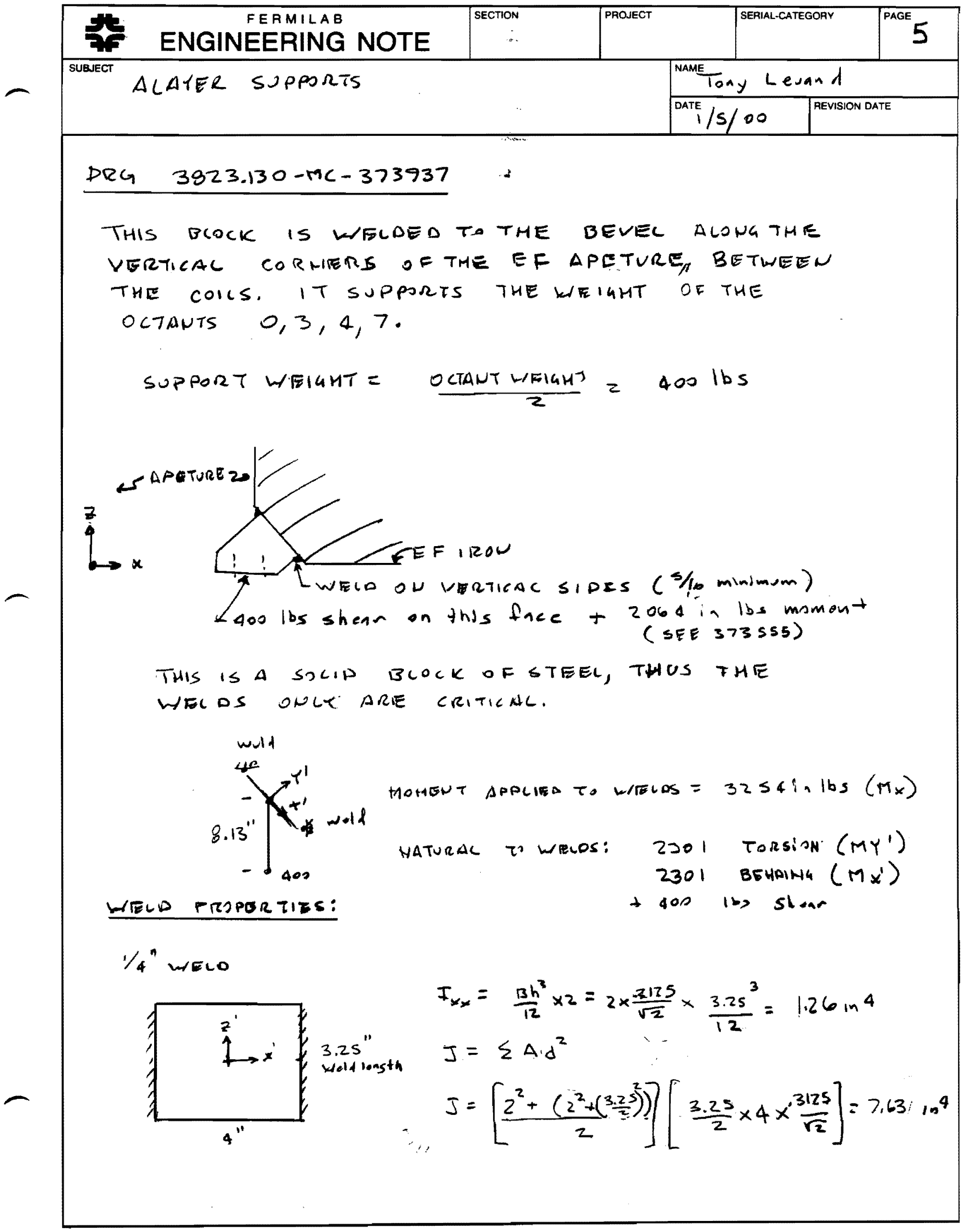




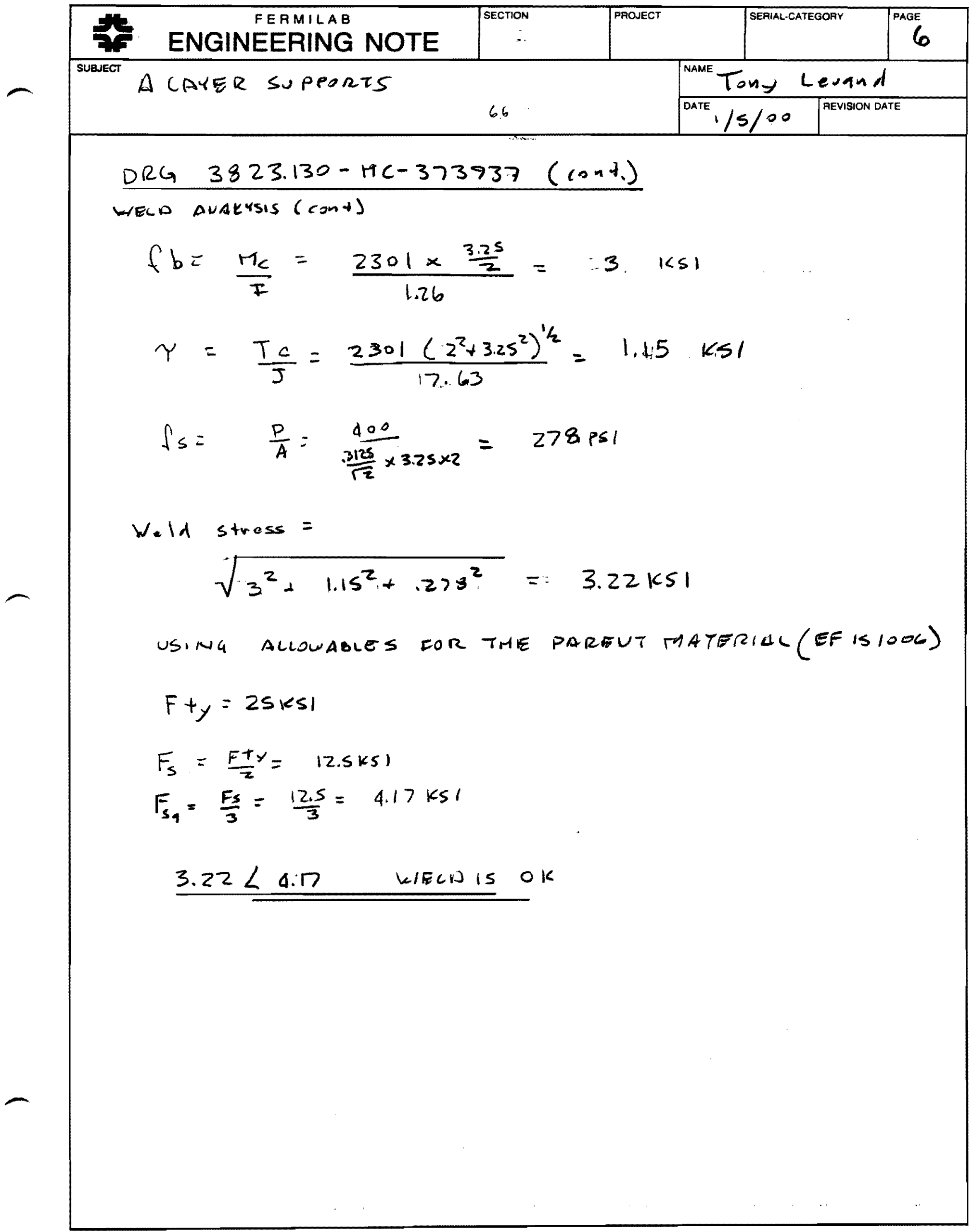




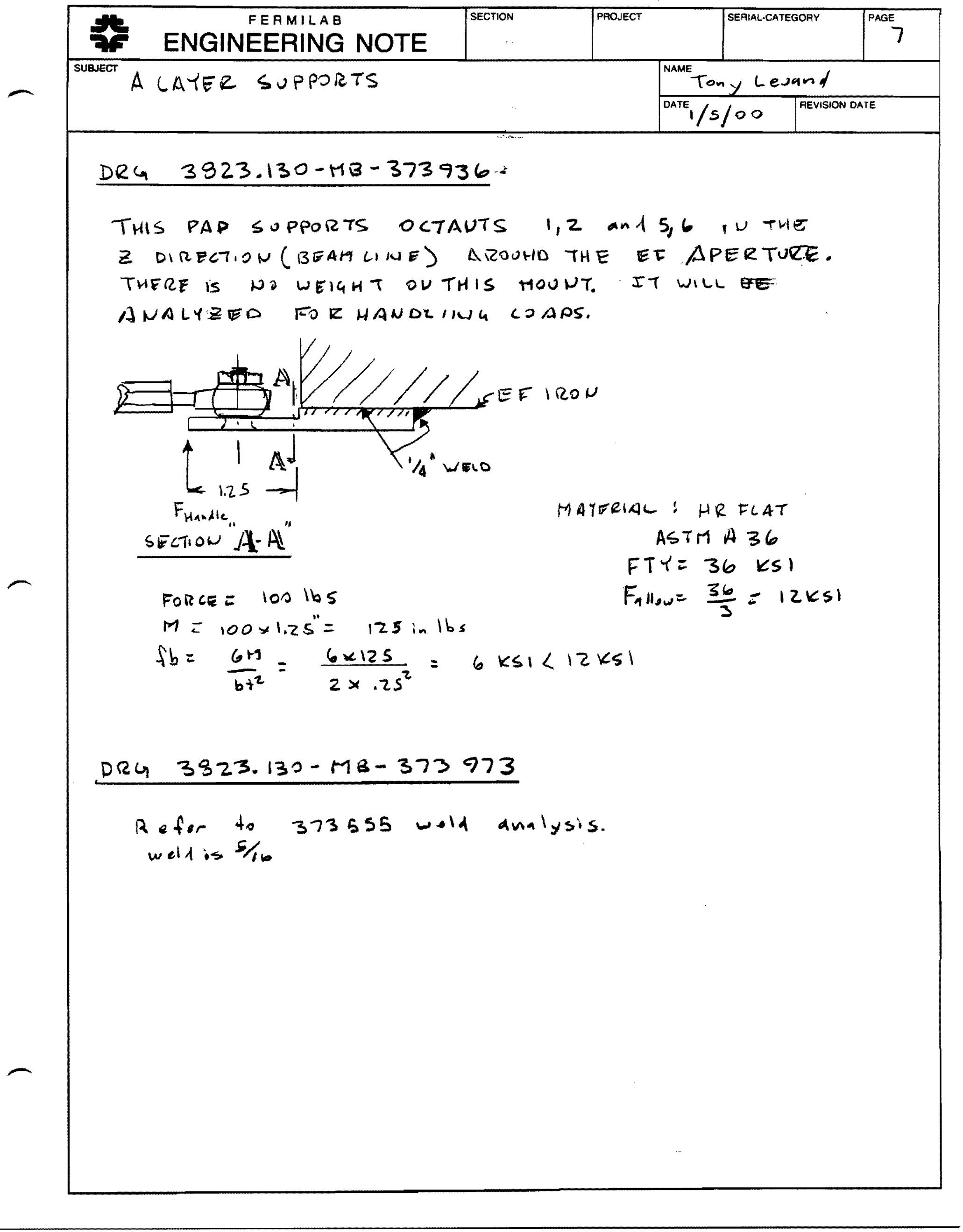




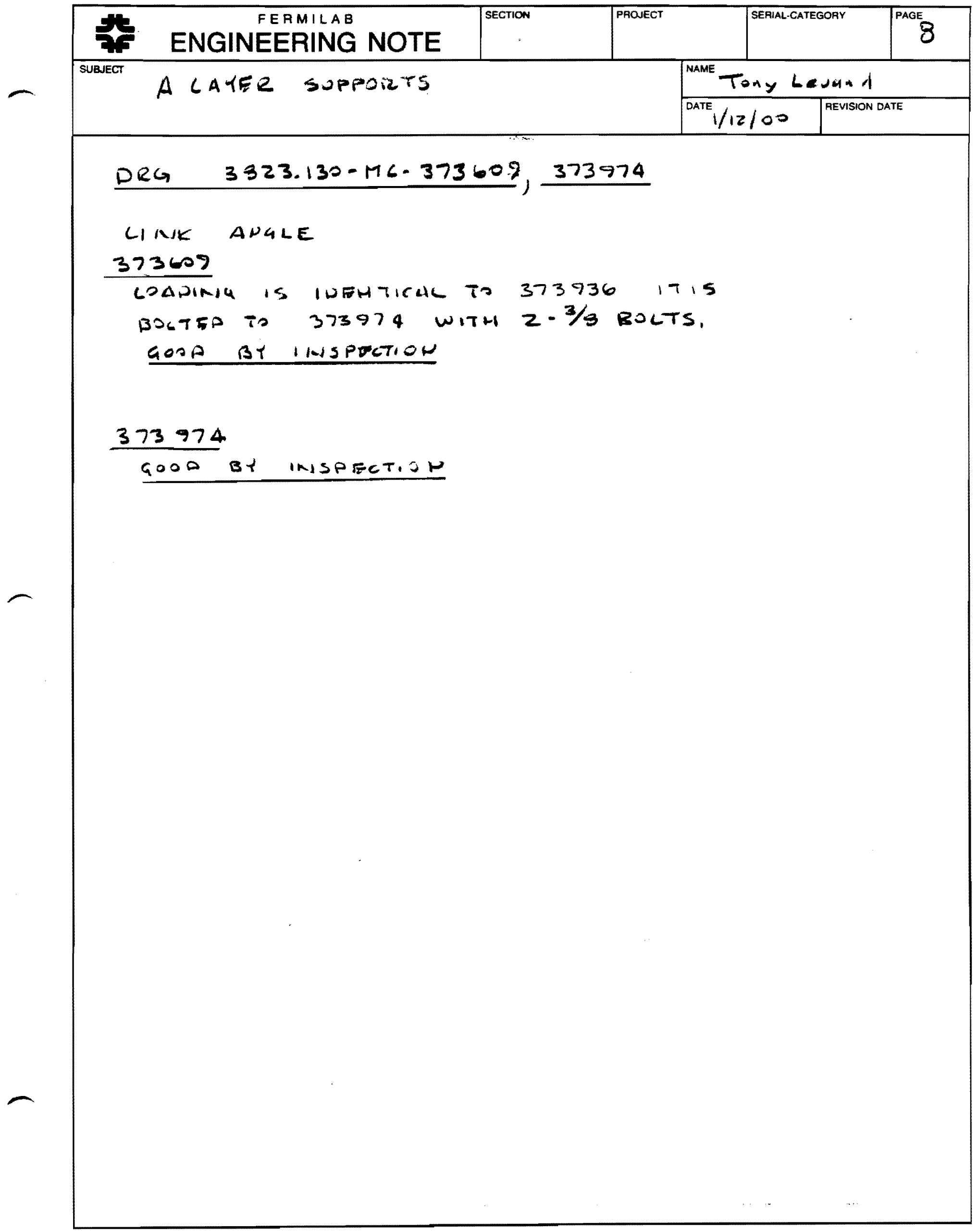




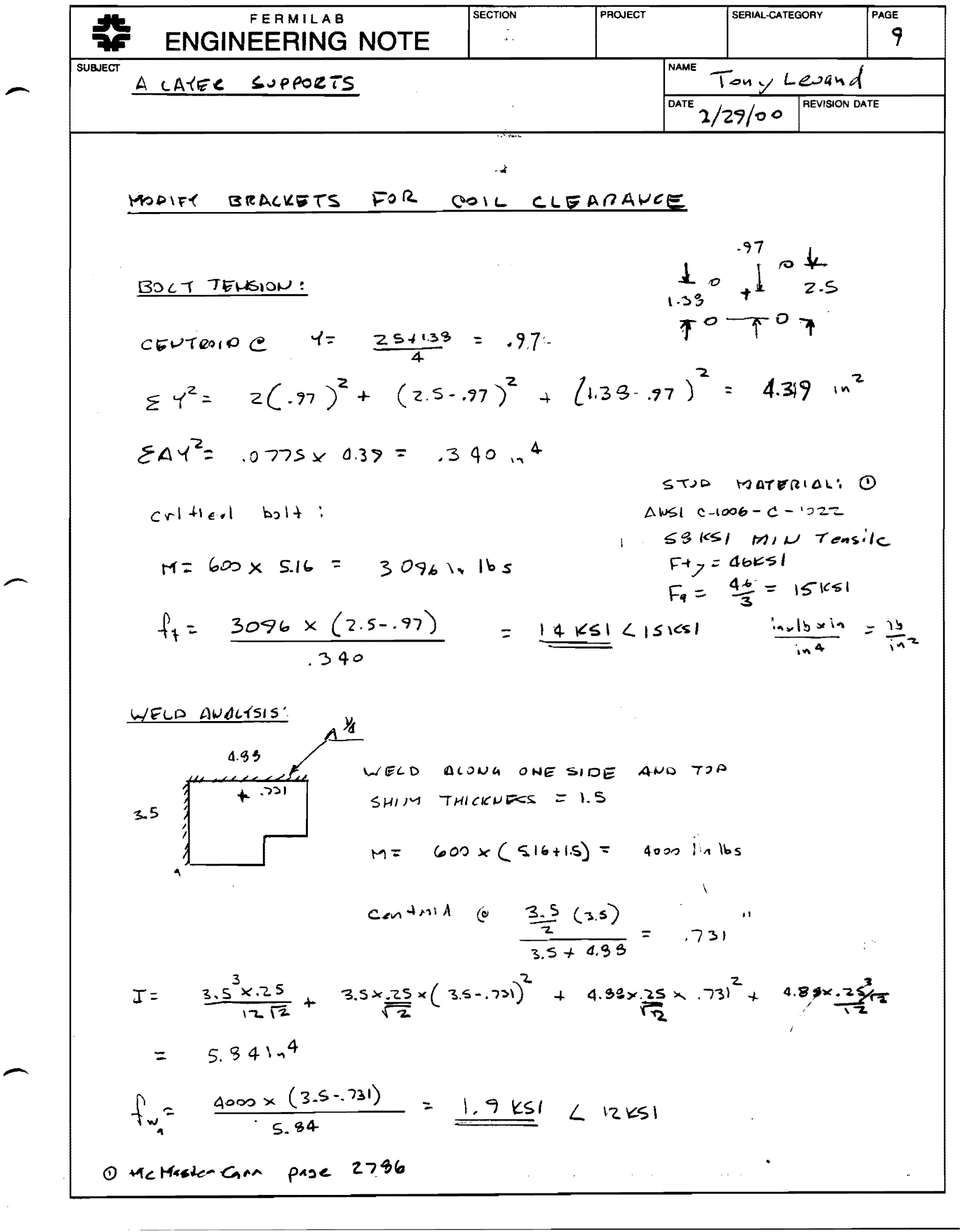




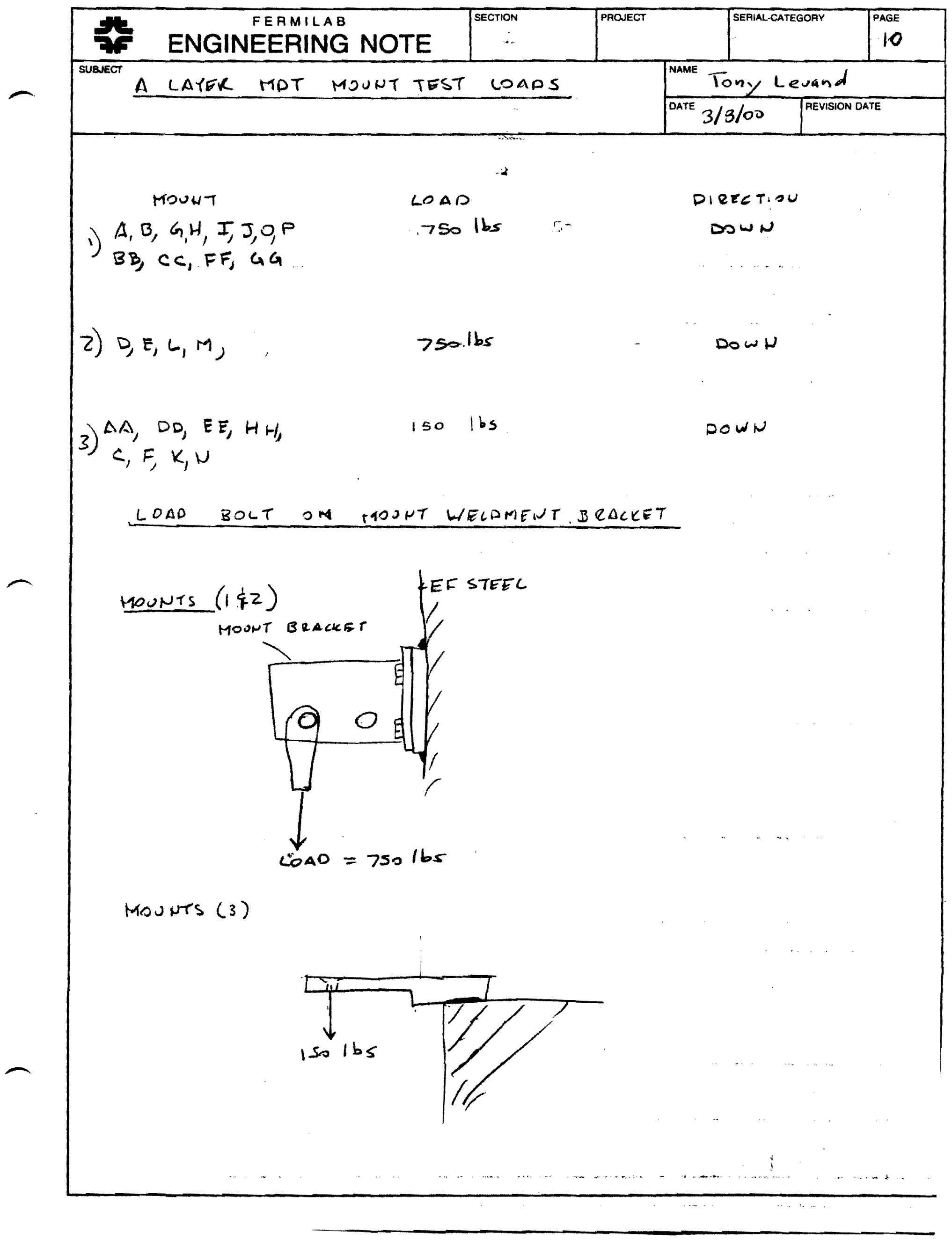

